\title{
Construction of Dissection Protocols as a Learning Object for Teaching Comparative Animal Anatomy
}

\author{
Andréia Passos Pequeno \\ ${ }^{1}$ Chair of Animal Anatomy, School of Veterinary Medicine, Faculty of Health Sciences, Universidad Nacional de Costa Rica (UNA)
}

Disclosure and conflicts of interest: none to be declared by the author

\begin{abstract}
Introduction: learning objects allow meaningful learning through the use of a dynamic methodology that greatly increases students' motivation and makes learning anatomy more effective. The purpose of the present study was to develop dissection protocols as a learning object for the teaching of Comparative Anatomy, by students of the Anatomy of Domestic Animals II course of the School of Veterinary Medicine of the Universidad Nacional de Costa Rica..

Material and Methods: a total of 25 students in the course participated in the definition of dissection protocols for bovine, equine, canine and feline species, presented as texts accompanied by photographs of dissections, as well as explanatory videos for each of the species and their body regions. At the end of the course participating students participated in a survey with objective questions about the process of constructing learning objects.

Results: a total of 6 dissection protocols reported in text and atlas formats were prepared, accompanied by explanatory videos. The 25 students who participated in this teaching experience participated voluntarily in the survey.

Conclusion: the definition of dissection protocols as a learning object contributed to a better understanding of theoretical concepts of anatomy and development of manual skills, improving motivation and learning of the subject matter of this discipline.
\end{abstract}

Keywords: Anatomy; Dissection; Animals; Learning Object; Veterinary Science.

\section{Introduction}

The implementation of new approaches to teaching, such as plastinated anatomical pieces, 3D printing technology, multimedia programs, medical imaging modules, and virtual reality has significantly simplified the process of learning anatomy. ${ }^{1,2}$ In fact, many universities around the world have already substantially reduced or abandoned dissection of cadavers in favor of other teaching methods. ${ }^{2,3}$

However, studies show the importance of an integrated approach that combines the strengths of traditional teaching methods such as cadaveric dissections with new methods for learning anatomy that meet the needs of modern anatomy students. ${ }^{4}$ It is also important to note that students believe that practical study of cadavers is essential to better understand and correct erroneous perceptions of theoretical concepts and/or variations in topographic anatomy. ${ }^{5,6}$

Despite the time and cost constraints necessary for dissection sessions, as well as the need for qualified teaching staff, it is essential to realize that cadaveric dissection plays an integral role in medical anatomy education. Dissection provides students with the opportunity for gradual learning, accompanied by the development of important skills and knowledge about the three-dimensional nature of the human and animal body. ${ }^{2,7,8}$

Studies have also revealed the importance of involving students in the creation of their own educational tools, and the construction of digital learning materials must therefore evolve from being a unidirectional and imposed process to one that is bidirectional and socialized. This teaching strategy greatly increases students' motivation, making it the most effective method for learning anatomy. ${ }^{5}$ Learning objects (LOs) have extremely relevant characteristics such as the ability to be reused at different times and in different learning contexts; the potential for generativity, which allows simultaneous access by a large number of people; flexibility, with the possibility of creating new versions; and scalability, with the possibility of being split into smaller parts that can be reused to support new individual instructional goals, which is a very common practice among teachers. ${ }^{9}$

Based on the points discussed previously and a conviction that construction of LOs has a great potential for improving the impacts of dissection in the teaching of veterinary anatomy, a LO construction methodology was designed for teaching of the topographic anatomy of bovine, equine, canine and feline species, in which students became the authors of their own learning materials during several dissection sessions. 


\section{Material and methods}

In the first class of the Anatomy of Domestic Animals II course offered to students in the second year of career of veterinary medicine, the course program was presented, and the 25 students enrolled in the course were asked to divide themselves into 5 groups of 5 students. Each group was responsible for the dissection of a cadaver previously preserved in saturated saline, following the instructions of the professor in charge.

Initially a dog, a cat, three calf fetuses and a horse fetus were preserved according to the saturated saline solution method. After the theoretical classes for each anatomical region, the students were instructed to dissect the specimens following a protocol previously prepared by the course professor.

The learning object (LO) consisted of:

1. Photographs of anatomical regions and their structures.

2. Dissection videos by regions and anatomical planes.

3. A written document in Word ${ }^{\circledR}$ format, referred to as the "Dissection Guide."

In each anatomical region, for each anatomical plane to be dissected, students were required to follow the recommended dissection protocol, recognize the exposed structures, identify muscle insertion sites, describe and, in some cases, simulate their movements in case of muscle contraction, and identify adjacent structures such as blood and lymph vessels, nerves, glands, and lymph nodes.

In addition to the dissection protocol, classes and photographs of previous dissections by the responsible professor were used as recommended learning resources for the students. The use of some animal anatomy websites from universities, such as University of Minnesota and Universidad de Murcia, was also recommended, as well as textbooks and animal anatomy atlas. However, each working group also carried out its own bibliographic search, according to the species under study.

The photographic records and videos of the dissection stages were carried out during the four hours of practical classes of the Anatomy II course, as well as during the three hours designated for independent study per student per week, as established in the course program. The dissected cadaver was used to teach practical classes and for laboratory tests.

The entire process was accompanied by the professor of the course both in person during the dissections and using a mobile text messaging app (WhatsApp ${ }^{\circledR}$ ) to send photographs, videos, texts and audios, as well as questions, comments and corrections. Therefore, after editing the photos and videos of each anatomical region, the students sent their work to the professor through WhatsApp ${ }^{\circledR}$ for correction and feedback. After corrections were done, the works were sent back to each group for editing.

The deliverable for each group was an internet link shared with the professor of the course, organized by sections (folders) of photos, videos and the "Dissection Guide" for the species being dissected.

The qualification of LOs was carried out by a rubric, according to the following categories: dissection quality and visible structures; quantity of anatomical plans, quality of the photos, quality and organization of the videos and dissection guide (Table 1).

Table 1. Rubric for the qualification of the Los

\begin{tabular}{|c|c|c|c|c|}
\hline Category & Excellent & Good & Regular & Insufficient \\
\hline $\begin{array}{l}\text { Dissection } \\
\text { quality and } \\
\text { visible } \\
\text { structures }\end{array}$ & $\begin{array}{l}100-90 \% \text { of the } \\
\text { anatomical structures } \\
\text { (mm., aa., vv., nn., ...) } \\
\text { are fine delimited } \\
\text { anddissected. }\end{array}$ & $\begin{array}{l}80-70 \% \text { of the } \\
\text { anatomicalstructures ( } \mathrm{mm} ., \\
\text { aa., vv., nn.,...) are fine } \\
\text { delimited and dissected. }\end{array}$ & $\begin{array}{l}60-50 \% \text { of the anatomical } \\
\text { structures ( } \mathrm{mm} ., \text { aa., vv., } \\
\text { nn.,.) are fine delimited and } \\
\text { dissected. }\end{array}$ & $\begin{array}{l}\text { less than } 40 \% \text { ofthe anatomical } \\
\text { structures (mm., aa., vv., nn., } \\
\text {... are fine delimited and } \\
\text { dissected. }\end{array}$ \\
\hline $\begin{array}{l}\text { Quantity of } \\
\text { anatomical plans }\end{array}$ & $\begin{array}{l}\text { Explore all recommended } \\
\text { anatomical planes. }\end{array}$ & $\begin{array}{l}\text { Explore } 80-70 \% \text { of the } \\
\text { recommended anatomical } \\
\text { planes. }\end{array}$ & $\begin{array}{l}\text { Explore } 60-50 \% \text { of the } \\
\text { recommended anatomical } \\
\text { planes. }\end{array}$ & $\begin{array}{l}\text { Explore less than } 40 \% \text { of the } \\
\text { recommended anatomical } \\
\text { planes. }\end{array}$ \\
\hline $\begin{array}{l}\text { Quality of } \\
\text { thephotos }\end{array}$ & $\begin{array}{l}\text { Complies with } 100 \% \\
\text { of the recommended } \\
\text { photos. Follow the } \\
\text { recommended format. } \\
\text { Photos of very good } \\
\text { quality (sharpness, } \\
\text { zoom, use of black or } \\
\text { white background, clean } \\
\text { work area) and very well } \\
\text { edited. }\end{array}$ & $\begin{array}{l}\text { Complies with } 80-70 \% \text { of } \\
\text { the recommended photos. } \\
\text { Follow the recommended } \\
\text { format. Photos of good } \\
\text { quality (sharpness, zoom, } \\
\text { use of black or white } \\
\text { background, clean work } \\
\text { area) and well edited. }\end{array}$ & $\begin{array}{l}\text { Complies with } 60-50 \% \text { of } \\
\text { the recommended photos. } \\
\text { Follow the recommended } \\
\text { format. Photos of good } \\
\text { quality (sharpness, zoom, } \\
\text { use of black or white } \\
\text { background, clean work } \\
\text { area) and well edited. }\end{array}$ & $\begin{array}{l}\text { Complies less than } 40 \% \text { of the } \\
\text { recommended photos. It does } \\
\text { not follow the recommended } \\
\text { format. Low quality } \\
\text { photographs (sharpness, } \\
\text { zoom, use of white or black } \\
\text { background, clean work area) } \\
\text { and weak editing. }\end{array}$ \\
\hline $\begin{array}{l}\text { Quality and } \\
\text { organization of } \\
\text { the videos and } \\
\text { dissection guide }\end{array}$ & $\begin{array}{l}\text { Content with } 100 \% \text { of } \\
\text { the correct information. } \\
\text { Follow } \\
\text { therecommendedformat. }\end{array}$ & $\begin{array}{l}\text { Content with } 80-70 \% \text { of the } \\
\text { correct information. Follow } \\
\text { the recommended format. }\end{array}$ & $\begin{array}{l}\text { Content with } 60-50 \% \text { of the } \\
\text { correct information. Follow } \\
\text { the recommended format. }\end{array}$ & $\begin{array}{l}\text { Content with less than } 40 \% \text { of } \\
\text { the correct information. It does } \\
\text { not follow the recommended } \\
\text { format. }\end{array}$ \\
\hline
\end{tabular}


At the end of the course the students that created the LOs responded anonymously to a survey prepared by the course professor for the evaluation of the construction process of the LO used, with a response on a Likert scale with 3 options (poor, adequate and good).

\section{Results}

Six different dissection protocols were developed for studying the topographic anatomy of bovine, equine, canine and feline species. For bovine species, two different protocols were developed, for dissection of the thoracic and abdominal cavities. Each protocol consisted of a written document composed of text accompanied by images (Fig. 1), which was the basis for the soundtracks used in the videos and contained six chapters referring to the following body regions: head, neck, anterior limb, posterior limb, thorax and abdomen.

For each chapter, the protocol for dissection of the skin was described first, followed by the guides for the dissection of each of the anatomical planes and their structures. Some animals had their blood and lymphatic vessels, as well as nerves, colored to facilitate their identification.

The groups that dissected animal fetuses were those that encountered the greatest difficulties, and this was taken into consideration when qualifying the work. The decision to use fetuses in advanced stages of gestation was based on cost. Bovine fetuses were all donated from slaughterhouses, while the equine fetuses, also from slaughterhouses, were purchased for a much lower cost than that of an adult animal. However, the students were oriented as to the difference between dissecting a fetus and an adult animal, and the results of the dissection, as well as the photos and videos, were highly satisfactory (Fig. 2 and 3$)$.

When editing the videos, each structure is accompanied by its name in both Spanish and Latin, according to the Veterinary Anatomical Nomenclature (NAV, 2017) (Fig. 4).

In general, all groups managed to build excellent dissection protocols, with the groups in charge of the dissection of the fetuses facing the biggest challenges - for reasons already mentioned.

At the end of the course, the 25 students who participated in this study answered the survey, of which $68 \%$ considered to be good the division of written resources, photographs and videos and $32 \%$ classified it as adequate. Regarding the use of the WhatsApp ${ }^{\circledR}$ application as a means of communication between the group members and the teacher, $44 \%$ rated it as being good; $40 \%$ considered it to be adequate, and $16 \%$ rated it as poor. When asked about the criteria used for evaluating the construction of the LO, $76 \%$ of the students considered them to be good and $24 \%$ of the respondents classified it as adequate. Eighty per cent (80\%) of the respondents considered the benefit of the construction of LOs to be good for their learning process, while $20 \%$ rated it as adequate. Finally, $92 \%$ of the students stated that the creation of resources (written text, photographs and videos) motivated them to study Anatomy (Fig. 5).

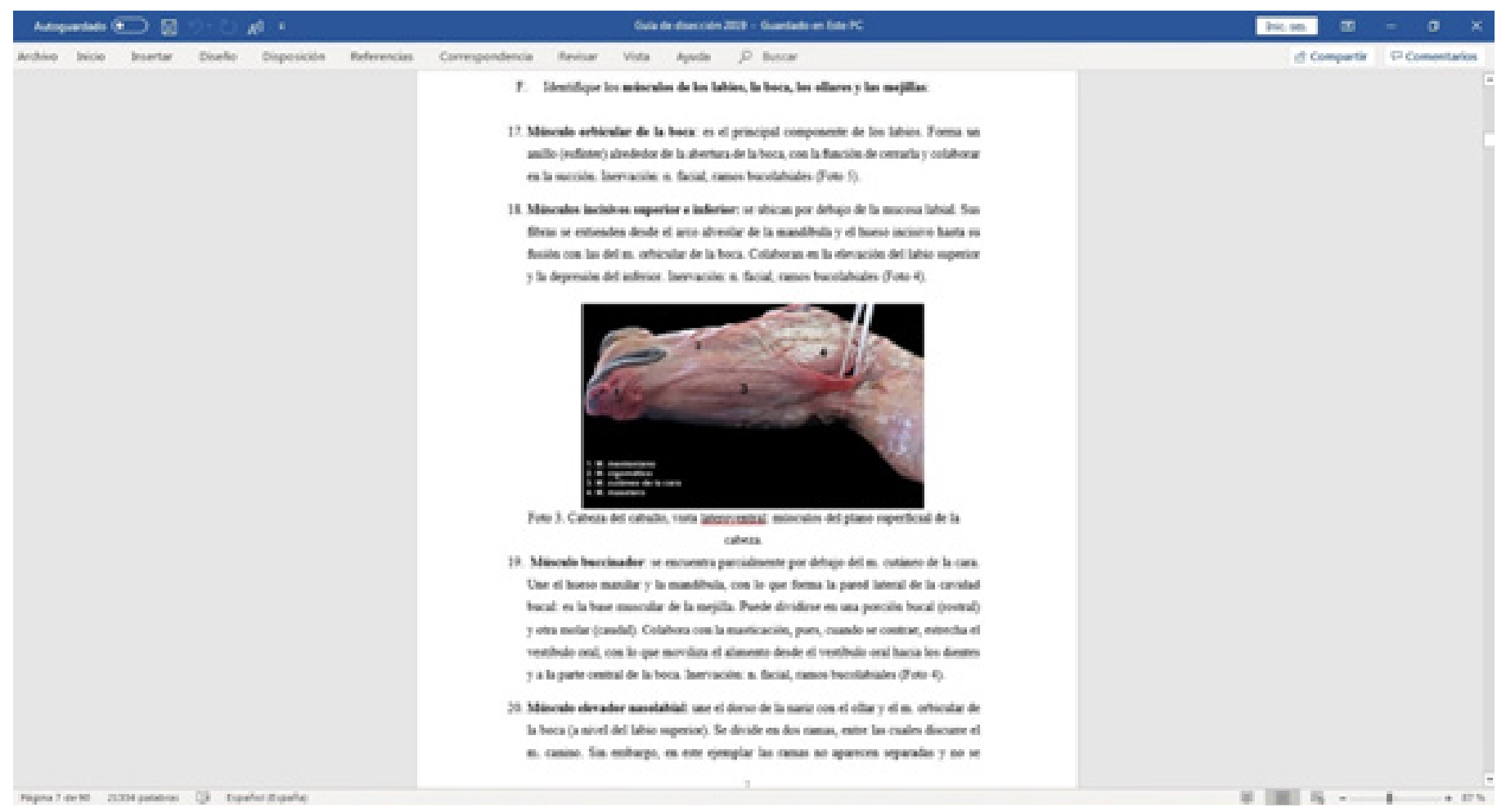

Figure 1. Image from the document "Horse dissection guide" 


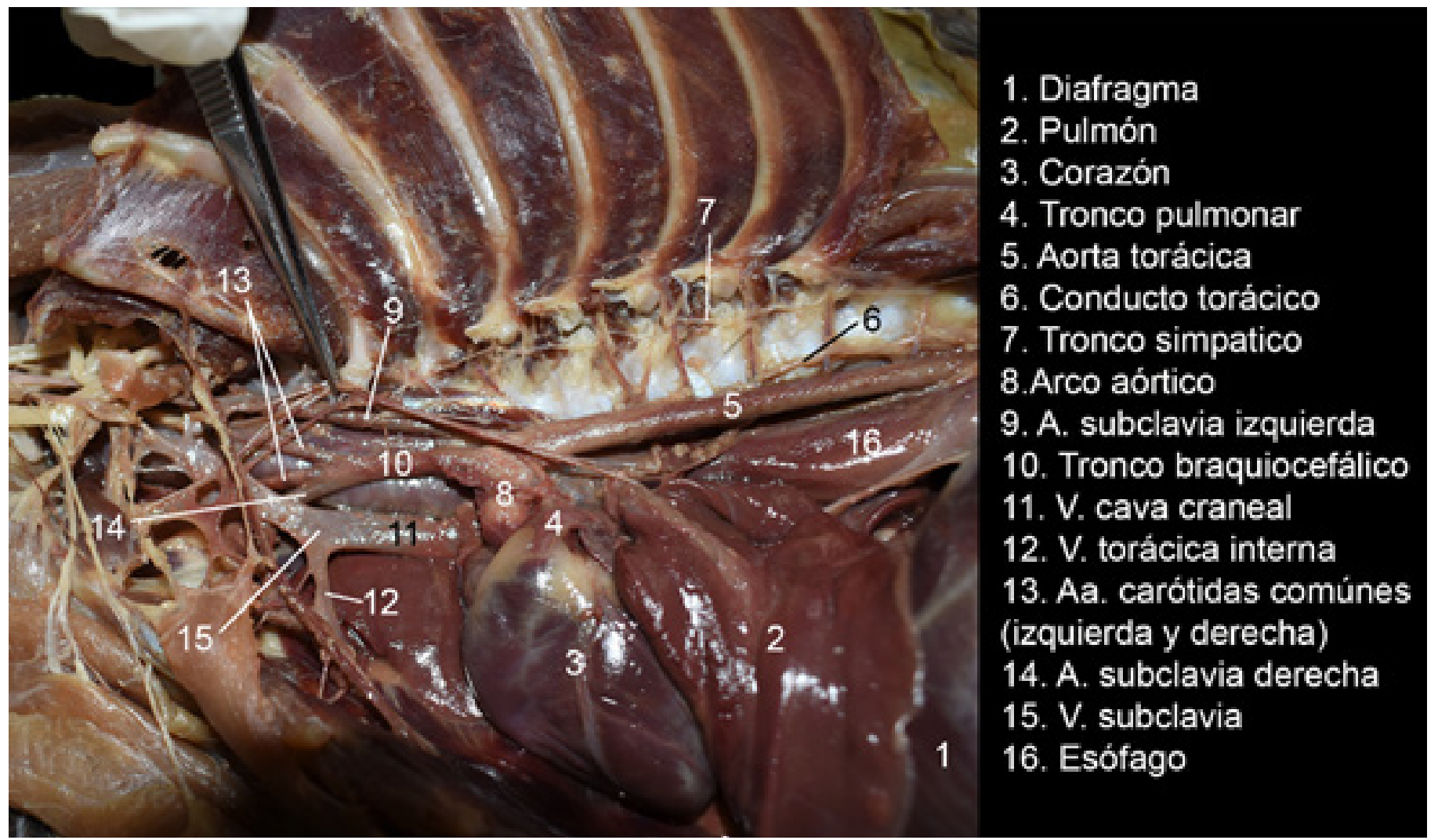

Figure 2. Photograph used in the document "Cat dissection guide"

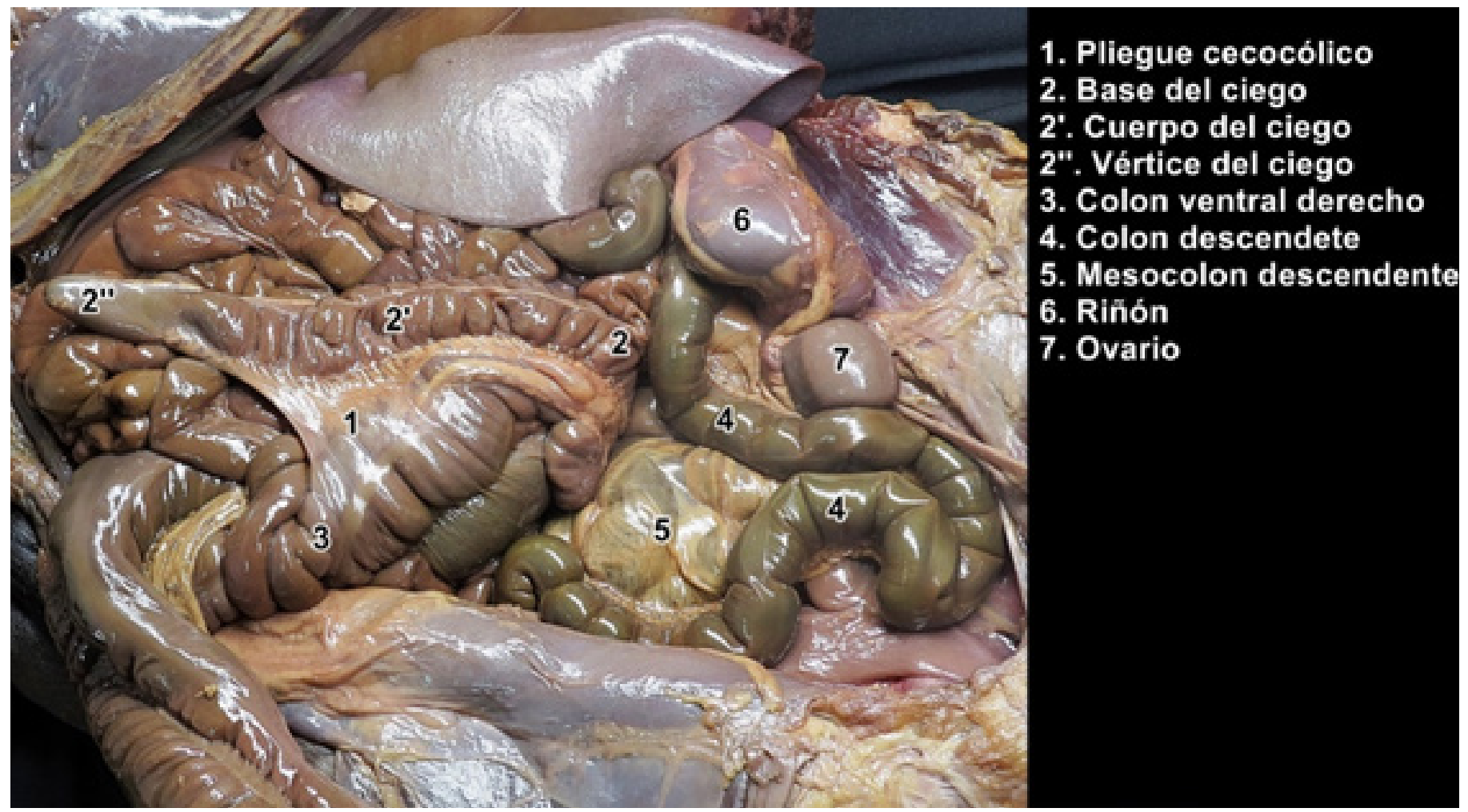

Figure3. Photograph used in the document "Horse dissection guide" 


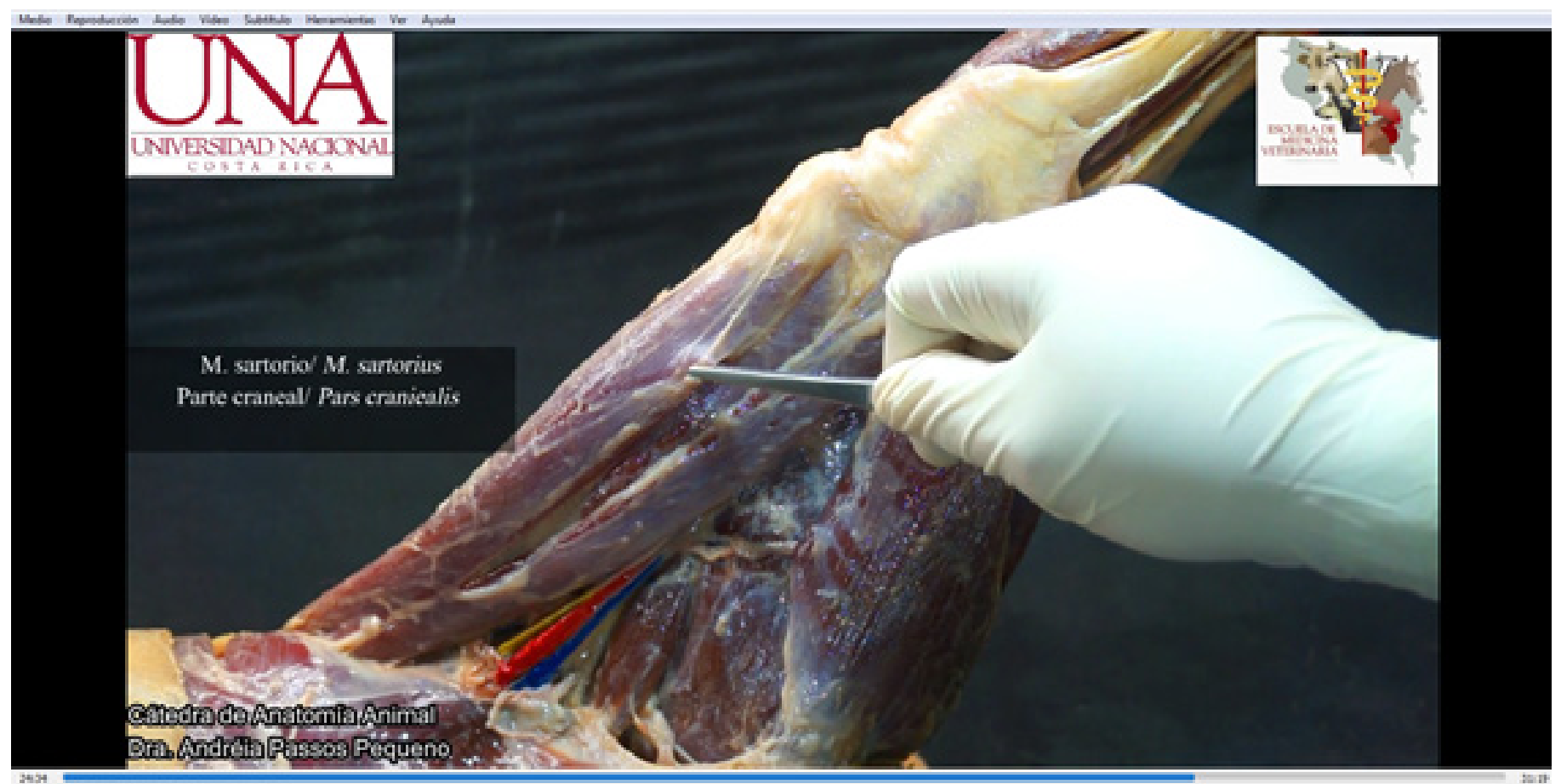

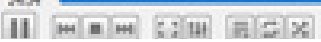

Figure 4. Image from an explanatory video for the pelvic limb of a dog.

Has the development of these materials (written text, photographs and videos) motivated you to study anatomy?

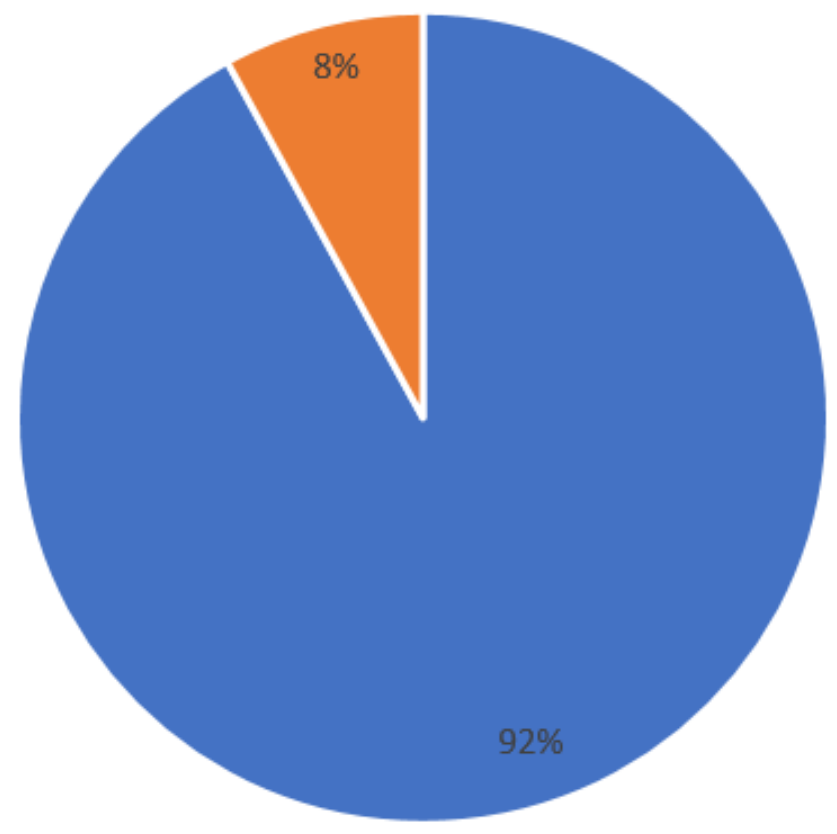

- Yes $\quad$ No

Figure 5. Graphic corresponding to one of the survey questions 


\section{Discussion}

The use of technological tools such as computers, smartphones, software, 3D gaming technology, and augmented virtual reality, has allowed health educators to use high quality images, sophisticated training tools and interactive computer programs that simulate or project the realities of human or animal anatomy in the classroom. What were once regarded as advanced imaging methods and technologies are now considered routine in many universities. .,10 $^{5}$

All these tools are undoubtedly an important support for the practical activities involved in an anatomy course. However, dissection as an integral tool in the training of health professionals cannot be ignored, nor is there an acceptable substitute for dissection. Dissection teaches essential skills that support a student's development across the spectrum of medical education. ${ }^{6,10}$ In addition, it is known to greatly increase students' motivation for acquiring an adequate knowledge of anatomy.

These findings reinforce the results obtained in this study, in which technological tools such as cameras, computers, programs for editing photos, audios and videos were used for the creation of learning objects derived from the dissection of cadavers. While dissecting, the students were also constructing study materials that would be useful for themselves, and which can also be used as guide for future generations of students.

As was the case for the students surveyed by Bucarey \& Álvarez (2006), the students who participated in this study consider the creation of their LOs as having motivated them to learn anatomy and having helped them to learn about anatomy more effectively. This confirms pedagogical theories on the construction of knowledge using Information and Communications
Technologies (ICTs) as facilitators of learning.

Furthermore, the materials that were created will be of great help for the orientation of future generations of students. Although there is a great deal of material referring to the anatomy of domestic mammals, there is no description in the literature of a dissection protocol that covers all of the species studied in this investigation and preserved according to the saturated saline solution method. Considering that this method of conservation has already been used successfully in the courses of the Chair of Anatomy of the school of veterinary medicine of the Universidad Nacional de Costa Rica, it is convenient to have photos and videos of dissections that use this same method. This confirms the comments of Wiley (2000), who highlighted the possibility of reusing materials at different times and in different learning contexts.

\section{Conclusion}

The development of LOs through dissection increased student motivation and facilitated the learning of comparative topographic anatomy. In addition, it provided future generations of students with a practical guide for the dissection of different species of domestic mammals from cadavers preserved with saline solution.

\section{Acknowledgements}

The author would like to thank the students of the Domestic Animals Anatomy II course, I cycle of 2019 for participating in the creation of LOs, as well as for voluntarily responding to surveys. The author acknowledges and thanks Mr. Heiner Serrano Alfaro, technician of the Chair of Anatomy for his dedication and collaboration in the preparation of the cadavers.

\section{References}

1. Smith CF, Tollemache N, Covill D, Johnston M. Take away body parts! An investigation into the use of 3D-printed anatomical models in undergraduate anatomy education. Anat Sci Educ. 2018;11(February):44-53. doi:10.1002/ase.1718

2. Jeyakumar A, Dissanayake B, Dissabandara L. Dissection in the modern medical curriculum: An exploration into student perception and adaptions for the future. Anat Sci Educ. 2019. doi:10.1002/ase.1905 3. Memon I. Cadaver dissection is obsolete in medical training! A misinterpreted notion. Med Princ Pract. 2018. doi:10.1159/000488320 4. Hu M, Wattchow D, de Fontgalland D. From ancient to avant-garde: a review of traditional and modern multimodal approaches to surgical anatomy education. ANZ J Surg. 2018;88:146-151. doi:10.1111/ans.14189 5. Bucarey S, Álvarez L. Metodología de construcción de objetos de aprendizaje para la enseñanza de anatomía humana en cursos integrados [Methodology for building learning objects for teaching human anatomy in integrated courses]. Int J Morphol.
2006;24(3):357-362.

6. Flack NAMS, Nicholson HD. What Do Medical Students Learn from Dissection? Anat Scien. 2017;11(4):325-335. doi:10.1002/ase.1758

7. Bucarey S, Álvarez L. Metodología de construcción de objetos de aprendizaje para la enseñanza del hígado humano [Methodology of construction of learning objects for teaching of the human liver]. In: IX Taller Internacional de Software Educativo TISE 2004. ; 2004:41-48. 8. Johnson JH. Importance of Dissection in Learning Anatomy: Personal Dissection Versus Peer Teaching. Clin Anat. 2002;44(June 2000):38-44. doi:10.1002/ca.1090

9. Wiley DA. Connecting learning objects to intructional design theory: A definition, a metaphor, and a taxonomy. In: The Instructional Use of Learning Objects. ; 2000:1-35.

10. Pawlina W, Lachman N. Dissection in Learning and Teaching Gross Anatomy: Rebuttal to McLachlan. Anat Rec Part B New Anat. 2004;281B:9-11. doi:10.1002/ar.b.20038
Received: August 8, 2019

Accepted: December 6, 2020
Corresponding author

Sávio Siqueira

saviolanasiqueira@gmail.com 